\section{Can the promotion of post-exposure prophylaxis following sexual exposure to HIV (PEPSE) cause harm?}

\section{J Richens, S G Edwards, S T Sadiq}

\section{Health policy decisions should be based on sound evidence}

$\mathrm{S}$ ustained increases among homosexual men of unsafe sexual behaviour, sexually transmitted infections, and HIV have caused much concern. ${ }^{1}$ HIV transmission among homosexual men continues despite the use of antiretroviral therapy that lowers infectiousness. ${ }^{2}$ The idea that "treatment optimism" has led to "behavioural disinhibition" has attracted much attention although recent data suggest it is by no means the whole story. ${ }^{3}$

Guidelines for the administration of antiretroviral drugs as post-exposure prophylaxis following non-occupational or sexual exposure (termed nPEP in the United States and PEPSE in the United Kingdom) have been drawn up in both the United Kingdom ${ }^{4}$ and the United States. ${ }^{5}$ These guidelines offer advice on when to give prophylaxis and to whom. Both guidelines acknowledge that the evidence in support of the recommendations is not watertight. Much of the evidence is inferred from retrospective data on occupational exposure, ${ }^{6}$ the use of antiretroviral therapy to reduce mother to child transmission of HIV, and on experimental simian immunodeficiency virus (SIV) and HIV-2 infections in macaques. ${ }^{89}$ The data suggest that PEPSE can reduce the risk of infection with HIV if administered promptly (less than 72 hours after exposure) and continued for 28 days. A non-randomised study among 202 homosexual men provided with access to PEPSE in Brazil suggested that there were $81 \%$ fewer seroconversions among those who took medication but was still not conclusive..$^{10}$ Other research suggests most homosexual men who receive PEPSE are more careful for periods of up to two years. ${ }^{11}$ Waldo et al were unable to demonstrate that the availability of PEP in San Francisco was increasing risk behaviour in homosexual men generally. ${ }^{12}$ The most recent health economic evaluation of PEPSE in the United States has concluded that PEP for sexual or injection drug exposure would be cost effective across 96 metropolitan areas. ${ }^{13}$ In general, studies suggest that maximum cost effectiveness would be achieved if PEPSE were given following receptive anal intercourse with a partner at high risk of infection or high risk exposures with a partner known to be infected. Even in San Francisco, 217 homosexual men reporting unprotected receptive anal intercourse with a partner of unknown status would need to be treated with PEPSE to prevent one transmission. ${ }^{13}$

We believe there is a distinct danger that the promotion of PEPSE could reinforce rising trends in risky sexual behaviour and might add to, rather than lessen, HIV transmission

A question that remains unanswered is what is the effect on the highest risk behaviours at a population level, of making PEPSE available on demand. The most desirable outcome (which is presumed by both guidelines) is that promoting PEPSE will cut rates of HIV infection in exposed individuals and reinforce safer sexual behaviour. Another possibility is that the promotion of PEPSE will make no difference to the epidemic with the numbers protected being counterbalanced by additional infections in men whose risk behaviour is increased by awareness of PEPSE but who then fail to obtain it or to respond to it. This outcome is consistent with the theory of risk homoeostasis developed by psychologist Gerald Wilde which posits that where an intervention to reduce risk is introduced, any protective gains tend to be counterbalanced by losses among individuals who increase their risk exposure too much. ${ }^{14}$ Should this prove to be the case with PEPSE, as we have suggested previously, ${ }^{15}$ then evaluations of the cost effectiveness of PEPSE could reach very different conclusions.

In the central London clinic where two of us work PEPSE was given to 48 patients in 2003 and 119 in 2004. The projected cost of PEPSE drugs alone for 2005 is $£ 180000$. Our HIV clinics are experiencing significant service and cost pressures since the introduction of the PEPSE guidelines and the publicity campaign by the Terence Higgins Trust, aimed at increasing awareness of PEPSE among homosexual men and encouraging them to approach clinics for advice. Since the start of the publicity campaign, relative increases in those obtaining PEPSE in a south west London clinic have been similar to those in north London despite this clinic not being identified in the publicity material.

The most serious question that has to be asked about PEPSE is whether it could cause net harm, protecting only a few individuals at the expense of adverse effects on behaviour and increased HIV transmission in the wider community. Increases in unsafe sexual behaviour among homosexual men have been reported in many countries in the past few years. The coincidence of this phenomenon with improved therapy has attracted much speculation and debate. ${ }^{1}$ With this background it seems legitimate to ask whether promoting PEPSE could exacerbate these trends. Clinicians, who rightly focus on helping the individual, may be reluctant to examine this possibility but it must be taken seriously when there is an expanding epidemic. We are concerned that there is pressure to make PEPSE available for homosexual men regardless of cost and without proper consideration of possible negative consequences on service delivery and HIV transmission. Local commissioners of HIV healthcare services in the United Kingdom have not been involved in decisions on the provision of PEPSE. We fear a backlash from unfavourable public opinion if large sums are to be spent without adequate evaluation on a measure of unproved efficacy at the individual level and with the potential to disinhibit safer sexual behaviour generally. Media interest could also lead to increasing numbers of heterosexuals seeking PEPSE, a situation in which PEPSE will rarely be cost effective in the United Kingdom.

Health policy decisions should be based on sound evidence. We conclude, firstly, that the scientific community has a responsibility to consider and attempt to measure the impact of PEPSE on clinical outcomes, behaviour, and attitudes, both at the individual and community level, in order to demonstrate whether it is beneficial or harmful. Secondly, until the evidence is clearer, we would question the wisdom of a national campaign publicising access to free provision of PEPSE. We believe there is a distinct danger that the promotion of PEPSE could reinforce rising trends in risky sexual behaviour 
and might add to, rather than lessen, HIV transmission.

\section{ACKNOWLEDGEMENTS}

This editorial was written following discussion with many colleagues. In particular we would like to thank the following for suggestions: Paul Benn, Jackie Cassell, Richard Gilson, John Imrie, Kevin Miles, Angela Robinson, Ian Weller, Mark Pakianathan, Helen Pritchitt, and Wendy Majewska.

Sex Transm Infect 2005;81:190-191. doi: 10.1136/sti.2005.014886

\section{Authors' affiliations}

J Richens, S G Edwards, Centre for Sexual Health and HIV Research, The Mortimer Market Centre, Mortimer Market, London WCIE 6AU, UK

S T Sadiq, Courtyard Clinic, St George's Hospital, Blackshaw Road, London SW17 OQT, UK

Correspondence to: John Richens, Centre for Sexual Health and HIV Research, The Mortimer Market Centre, Mortimer Market, London WC1E 6AU, UK; jirichens@gum.ucl.ac.uk

\section{REFERENCES}

1 Elford J, Bolding G, Davis $M$, et al. Trends in sexual behaviour among London homosexual men 1998-2003: implications for HIV prevention and sexual health promotion. Sex Transm Infect 2004;80:451-4.

2 Sadiq ST, Taylor S, Kaye S, et al. The effects of antiretroviral therapy on HIV-1 RNA loads in seminal plasma in HIV-positive patients with and without urethritis. AIDS 2002;16:219-25.

3 Elford J. HIV treatment optimism and high-risk sexual behaviour among gay men: the attributable population risk. AIDS 2004; 18:2216-7.

4 Clinical Effectiveness Group (British Association of Sexual Health, HIV). United Kingdom Guideline for the use of post-exposure prophylaxis for HIV following sexual exposure. www.bashh.org/ guidelines/draft_04/pepse\%5B1\%5D_010404.doc, accessed 21 Jan, 2005.

5 CDC. Antiretroviral postexposure prophylaxis after sexual, injection-drug use, or other nonoccupational exposure to HIV in the United States. MMWR 2005;54(RR02): 1-20.

6 Cardo DM, Culver DH, Ciesielski CA, et al. A case-control study of HIV seroconversion in health care workers after percutaneous exposure to HIVinfected blood: clinical and public health implications. N Engl J Med 1997;337:1485.

7 Wade NA, Birkhead GC, Warren BL, et al. Abbreviated regimens of zidovudine prophylaxis and perinatal transmission of the human immunodeficiency virus. N Engl J Med 1998:339:1409-14
8 Otten RA, Smith DK, Adams DR, et al. Efficacy of postexposure prophylaxis after intravaginal exposure of pig-tailed macaques to a humanderived retrovirus (human immunodeficiency virus type 2). J Virol 2000:74:9771-5.

9 Tsai CC, Emau P, Follis KE, et al. Effectiveness of post-inoculation PMPA treatment for prevention of persistent SIV infection depends critically on timing of initiation and duration of treatment. $J$ Virol 1998;72:4265-73.

10 Schecter M, Lago RF, Mendelson AB, et al. Behavioural impact, acceptability and HIV incidence among homosexual men with access to postexposure chemoprophylaxis for HIV $J$ Acquir Immun Defic Syndr 2004;35:519-25.

11 Martin JN, Roland ME, Neilands TB, et al. Use of postexposure prophylaxis against HIV infection following sexual exposure does not lead to increases in high-risk behavior. AIDS increases in high-ris
2004;18:787-92.

12 Waldo CR, Stall RD, Coastes TJ. Is offering postexposure prevention for sexual exposures to HIV related to sexual risk behaviour in gay men? AIDS 2000; 14:1035-9.

13 Pinkerton SD, Martin JN, Roland ME, et al. Costeffectiveness of HIV postexposure prophylaxis following sexual or injection drug exposure in 96 metropolitan areas in the United States. AIDS 2004; 18:2065-73.

14 Wilde GJS. Target risk. Dealing with the danger of death, disease and damage in everyday decisions, PDE Publications, 1994

15 Richens J, Imrie J, Copas A. Condoms and seat belts: the parallels and the lessons. Lancet 2000;355:400-3.

from a homosexual man of unknown HIV serostatus is $0.045 \%$, whereas the risk following receptive anal intercourse from a known HIV positive "donor" is at worst $3 \%$, and from an undetermined source $0.45 \%$. Is it ethical to withhold a potentially beneficial though not "AI" evidence based intervention in one situation (of higher risk) but provide it freely in the other? To do so would seem to challenge the basic biomedical ethical principles of justice and beneficence.

Richens et al quite rightly identify that one of the major concerns regarding the routine provision of PEPSE is the potential for a resulting change in risk behaviour such that individuals will engage in high risk activity in the knowledge that PEPSE is available. However, contrary to these concerns, all available data suggest that this is not the case. In the two studies that have examined behaviour after individuals have taken PEP the opposite appears to occur. In Brazilian MSM, risk behaviour declined over time (in both PEP users and non-users), ${ }^{2}$ and in San Francisco 73\% reported a decrease in high risk sexual acts. ${ }^{4}$ Clearly, there are limitations to these data. Firstly, it remains to be determined whether such changes in sexual behaviour occur in other settings (such as the United Kingdom). Secondly, these studies have only examined changes in behaviour in individuals who have received PEP and not the wider community. Those studies that have attempted to address the possible effects of availability of PEP have suggested that awareness does not result in an increase in risk taking. ${ }^{5}$ It is well efficacy. It is highly unlikely that a prospective randomised study to address involved in comparing these scenarios. For example, the risk to a healthcare worker following a needlestick injury 
recognised that risk behaviour has increased in MSM (and other groups) in recent years. Possible explanations for this change include treatment optimism, ${ }^{7}$ easier access to casual sexual partners (for example via the internet), ${ }^{8}$ and safe sex "burnout." individually are sufficient to explain behavioural changes, which is likely to result from a complex interplay of individual and societal factors. Within this milieu, it is highly unlikely that the provision of PEPSE will in itself be a significant driver of behavioural change at a population level, though studies to confirm this would be welcomed. In the meanwhile, there exists the opportunity at an individual level not only to provide a further method of HIV prevention, but also to seize this opportunity to screen and vaccinate for other sexually transmitted infections and offer risk reduction advice. Providing PEPSE may well act as a "wake up call" and have a beneficial effect on behaviour rather than a deleterious one.

Richens et al quite rightly raise issues regarding cost and service provision. These have been specifically addressed within the BASHH guidelines. Modelling from the United States ${ }^{10}$ has suggested that the provision of PEPSE is cost saving following unprotected receptive anal intercourse in men who have sex with men, and is cost effective in all other situations for which PEPSE is recommended within the BASHH guidelines. While the cost of providing PEPSE is not insignificant- $£ 600-£ 1000$ per patientthe cost of an individual with HIV infection is $£ 0.5-1$ million to the healthcare system and society. Richens et al acknowledge that no commissioner of health care was involved in the development of these guidelines. This is hardly unusual for guidelines that are intended for patient management. Surely the role of commissioners is to respond to the view of the medical profession (and allied professionals and service users) rather than to guide clinical decisions? Furthermore, it is of relevance that during a prolonged period of consultation, there has been not a single response to the BASHH guidelines from any purchaser of health care or health promotion. Commissioners will, however, no doubt become involved in the negotiation of funding for levels of service provision to respond to patient and clinical demandincluding the increased demand for PEPSE like any other service development. The data on increasing demand from Richens et al is to be welcomed in this respect and ongoing monitoring (such as via the NonoPEP study) remains vital to determine levels of service required, in addition to providing further data on behaviour and efficacy. Previous
PEPSE programmes in San Francisco ${ }^{11}$ and Sydney (Watson R, personal communication) have not resulted in a major demand on service capacity, but obviously the impact in the United Kingdom may be different. Richens et al question whether other individuals (such as heterosexuals) may present for PEPSE in situations where it will not be cost effective. The guidelines are clear in recommending PEPSE only where there is significant risk of the source individual being HIV positive.

Providing PEPSE may well act as a "wake up call" and have a beneficial effect on behaviour rather than a deleterious one

Richens et al question the publicity campaign by non-governmental organisations that accompanied the release of the draft BASHH guidance. It is noteworthy that surveys of those at highest risk of HIV transmission (that is, MSM) ${ }^{12}$ have shown that only $23 \%$ were aware of the possibility of PEPSE. (In this survey, it is also of relevance that only $1 \%$ had requested PEP despite this level of awareness.) It would seem difficult to justify maintenance of the current situation where availability of PEPSE is limited to those few who are aware of its existence, as to do so would result in a significant majority of those at risk being denied a potentially beneficial intervention on the grounds of ignorance alone. Furthermore, it should be noted that promotional material is clear that PEPSE remains unproved; is not $100 \%$ effective, and should not be used as a routine method of HIV prevention.

Richens et al do not comment on variations of practice in the absence of guidance. A previous study by the British Cooperative Clinical Group demonstrated that provision of PEPSE was highly variable across the United Kingdom. ${ }^{13}$ The development of national guidelines is therefore entirely consistent with ethical principles of equity and the ethos of a national healthcare system. The absence of any recommendation would result in the maintenance of the status quo-that is, variability of advice/management dependent upon the healthcare setting to which the individual presented.

The recommendations made by BASHH are similar to those made by the United States, France, Spain, and Australia. From a similar, if imperfect, body of evidence many countrieswhere HIV transmission is ongoing and antiretroviral therapy is available-are utilising such therapies as one method of HIV prevention. The BASHH guidelines state explicitly that the provision of PEPSE is only one strand of HIV prevention and should only be considered as a last measure where conventional and proved methods have failed. Monitoring of uptake and efficacy and research programmes to determine impact on behaviour are essential and guidance should be reviewed in the light of new data. In the interim, to ignore the issue and fail to produce guidance would seem to prolong inequity of service provision, delay the emergence of information to guide clinical decision making, and potentially withhold one extra tool in the battle to prevent new cases of HIV infection.

Sex Transm Infect 2005;81:191-192. doi: $10.1136 /$ sti.2005.015222

Correspondence to: M Fisher, Brighton and Sussex University Hospitals NHS Trust, Royal Sussex County Hospital, Brighton BN2 5BE, UK; martin.fisher@bsuh.nhs.uk

\section{REFERENCES}

1 Clinical Effectiveness Group (British Association of Sexual Health, HIV). United Kingdom Guidelines for the use of post-exposure prophylaxis for HIV following sexual exposure. www.bashh.org/guidelines/draft-04/ pepse\%B 1\%5D 010404.doc.

2 Praca Onze Study Team. Behavioural impact, acceptability, and HIV incidence amongst homosexual men with access to postexposure chemoprophylaxis for HIV. J Acquir Immune Defic Syndr 2004;35:519-25.

3 Schecter M. Occupational and sexual PEPbenefit/risk? 6th International Conference on Drug Therapy in HIV Infection, Glasgow, UK, 2002 (abstract PL 6.1).

4 Martin JN, Roland ME, Neilands TB, et al. Use of postexposure prophylaxis against HIV infection following sexual exposure does not lead to increases in high-risk behaviour. AIDS 2004; 18:787-92.

5 Waldo CR, Stall RD, Coates TJ. Is offering postexposure prevention for sexual exposures to HIV related to sexual risk behaviour in gay men? AIDS 2000; 14:1035-9.

6 Van der stratten A, Gomez CA, Saul L, et al. Sexual risk behaviours among heterosexual serodiscordant couples in the era of postexposure prevention and viral suppressive therapy. AIDS 2000; 14:F47-54.

7 Elford J. HIV treatment optimism and high-risk sexual behaviour among gay men: the attributable population risk. AIDS 2004; 18:2216-7.

8 Elford J, Bolding G, Sherr L. Seeking sex on the Internet and sexual risk behaviour amongst men using London gyms. AIDS 2001;15:1433-4.

9 Wolitski RJ, Valdiserri RO, Denning PH, et al. Are we headed for a resurgence of the HIV epidemic amongst men who have sex with men? Am J Public Health 2001:91:883-8.

10 Pinkerton SD, Martin JN, Roland ME, et al. Costeffectiveness of HIV postexposure prophylaxis following sexual or injection drug exposure in 96 metropolitan areas in the United States. AIDS 2004; 18:2065-73.

11 Kahn JO, Martin JN, Roland ME, et al. Feasibility of postexposure prophylaxis (PEP) against human immunodeficiency virus infection after sexual or injection drug use exposure: the San Francisco study. J Infect Dis 2001;183:707-14.

12 Sigma Research. Gay men's sex survey 2003. Accessible at: www.sigmaresearch.org.uk/ reports.html.

13 Giele CM, Maw R, Carne C, et al. Post-exposure prophylaxis for non-occupational exposure to HIV: current clinical practice and opinions in the United Kingdom. Sex Transm Infect 2002;78:130-2. 